\title{
Estabelecimento do amendoim forrageiro e dinâmica de espécies em vegetação campestre no litoral sul, Rio Grande do Sul
}

\author{
Establishment of forage peanut and dinamics of species in natural vegetation in south coast - \\ Rio Grande do Sul
}

Vivian Brusius Cassal ${ }^{\mathrm{I}}$ Élen Nunes Garcia ${ }^{I I}$ Pedro Lima Monks ${ }^{\mathrm{I}}$

RESUMO

Objetivou-se avaliar o efeito de aplicação de herbicida, sobressemeadura de azevém anual sobre o estabelecimento de amendoim forrageiro (Arachis pintoi) na dinâmica da vegetação em pastagem nativa. $O$ experimento foi desenvolvido de outubro de 2007 a novembro de 2008, na Estação Experimental Terras Baixas (ETB)-Embrapa Clima Temperado, Capão do Leão-RS. Os tratamentos foram arranjados em um delineamento de blocos completos ao acaso com parcelas subdivididas, com quatro repetições. As parcelas foram representadas pelos tratamentos com e sem herbicida (herbicida glifosato, na dosagem de 3,0L ha $\mathrm{h}^{-1}$ ). As subparcelas foram definidas pela ausência; presença de amendoim forrageiro e presença de amendoim forrageiro sobressemeado com azevém anual. A frequência das espécies da vegetação campestre não foi influenciada pela sobressemeadura de azevém. O estabelecimento de amendoim forrageiro Arachis pintoi é beneficiado pela aplicação de glifosato. Entretanto, é uma prática que pode provocar redução significativa de espécies de interesse forrageiro. A presença do azevém anual proporciona um ambiente favorável para o amendoim forrageiro durante o período de inverno.

Palavras-chave: Arachis pintoi, azevém, glifosato, forrageiras, plantas daninhas, fitossociologia.

\begin{abstract}
The objective of this study was to evaluate the practical application of herbicide, overseeded annual ryegrass for the establishment of forage peanut (Arachis pintoi) in natural vegetation. The experiments was conducted from October 2007 to November 2008, Estação Experimental Terras Baixas (ETB) Embrapa Clima Temperado, Capão do Leão - RS. The treatments were arranged in a randomized block design in split plots with four replications. The plots were represented by the
\end{abstract}

treatments with and without herbicide ( $3 L \mathrm{ha}^{-1}$ of commercial herbicide glyfosate). The subplots were defined by the absence of forage peanut, the presence of forage peanut, the presence of forage peanut overseeded with annual ryegrass. The frequencies of species of natural vegetation were not influenced by grazing and overseeded ryegrass. The establishment of forage peanut Arachis pintoi is benefited by the herbicide. However, it is a practice that causes a significant reduction of species of forage interest. The presence of annual ryegrass provides a favorable environment for forage peanut during the cool season.

Key words: Arachis pintoi, ryegrass, glyphosate, forage, weeds, phytosociology.

\section{INTRODUÇÃO}

A pastagem nativa do Rio Grande do Sul constitui um ecossistema bastante complexo em função das suas variadas condições edafo-climáticas, as quais podem definir comunidades vegetais totalmente diversas em composição botânica e potencial produtivo (BANDINELLI et al., 2003). A introdução de novas espécies nessa comunidade vegetal requer um condicionamento prévio para assegurar sucesso, buscando minimizar a competição da vegetação existente pois, quanto mais complexa for a estrutura de uma comunidade, maior será a dificuldade de uma espécie estranha para se estabelecer (RISSO \& BERRETTA, 1996). A presença de leguminosas na pastagem melhora a qualidade da forragem em relação à constituída somente por gramíneas, uma vez que a

'Departamento de Zootecnia, Universidade Federal de Pelotas (UFPel), Pelotas, RS, Brasil.

"Departamento de Botânica, UFPel, 96010-900, Pelotas, RS, Brasil. E-mail: vicassal@ibest.com.br. Autor para correspondência. 
produção animal a pasto é, de modo geral, determinada pela contribuição de leguminosas, pois o suprimento de nitrogênio é o principal fator limitante dentro do sistema solo-planta-animal (MARASCHIN, 1994).

$\mathrm{O}$ amendoim forrageiro (Arachis pintoi Krapov. \& W.C. Gregory) é uma leguminosa perene de verão, com hábito de crescimento prostrado e estolonífero, endêmica da flora brasileira (KRAPOVIKAS \& GREGORY, 1994). Estudos demonstram a adaptação do amendoim forrageiro, principalmente às condições da região sul do Rio Grande do Sul (NASCIMENTO, 2004). Entretanto, o lento estabelecimento inicial do amendoim forrageiro propicia maior aparecimento de plantas daninhas, comprometendo a rápida cobertura do solo e prejudicando o aproveitamento da pastagem (PARIS, 2006). Cynodon dactylon (L.) Pers e Eragrostis plana Nees são consideradas plantas indesejáveis em sistemas agrícolas e pecuários, dificultando a implantação de espécies, diminuindo os rendimentos de cultivos, a qualidade das forragens e a persistência das pastagens semeadas. Atualmente, no Brasil, o Glifosato é um dos herbicidas mais utilizados, devido ao seu amplo espectro de ação e elevada eficiência no controle de plantas daninhas (AMARANTE JUNIOR et al., 2002; MONQUERO, 2003). A sobressemeadura de espécies hibernais, sobre pastagem naturalizada, aumenta a produção, valor nutritivo e distribuição estacional da forragem (REIS \& FONTANELI, 2000). O azevém anual (Lolium multiflorum Lam.) é uma gramínea de fácil implantação, versátil, que pode ser utilizada como melhoradora de pastagens naturais (FLORES et al., 2008).

Objetivou-se avaliar o efeito da aplicação de herbicida e da sobressemeadura de azevém anual sobre o estabelecimento de amendoim forrageiro e na dinâmica da vegetação em área de vegetação campestre.

\section{MATERIAL E MÉTODOS}

O trabalho foi realizado no período de outubro de 2007 a novembro de 2008, na Estação Experimental Terras Baixas (ETB) da Embrapa Clima Temperado, no município de Capão do Leão - RS. O clima predominante na região é do tipo $\mathrm{Cfa}$, segundo Köeppen-Geiger, citado por Mota (1951), com verões quentes e invernos frios, apresentando temperaturas médias de $19,4^{\circ} \mathrm{C}$, com mínima absoluta de $5,1^{\circ} \mathrm{C}$.

$\mathrm{O}$ solo pertence à unidade de mapeamento Pelotas e é classificado como Planossolo hidromórfico eutrófico solódico (STRECK et al., 2008), sendo a análise química realizada antes do início do experimento, apresentando as seguintes características: $\mathrm{pH}$ em
$\mathrm{H}_{2} \mathrm{O}=4,8 ;$ pHSMP $=6,5 ; \mathrm{P}=48,8\left(\mathrm{mg} \mathrm{dm}^{-3}\right) ; \mathrm{K}=54$ ( $\mathrm{cmolc}$ $\left.\mathrm{dm}^{-3}\right) ; \mathrm{MO}=1,7 \% ; \mathrm{Al}=0,6\left(\mathrm{cmolc} \mathrm{dm}^{-3}\right) ; \mathrm{Ca}=0,6(\mathrm{cmolc}$ $\left.\mathrm{dm}^{-3}\right) ; \mathrm{Mg}=0,2\left(\mathrm{cmolc} \mathrm{dm}^{-3}\right)$, argila $=17 \%$, CTC 3,4 mol $_{\mathrm{c}}$ $\mathrm{dm}^{-3}$ e saturação de bases de $28 \%$. A área experimental possui aproximadamente um hectare, com a presença de capim Annoni-2 (Eragrostis plana Nees) e grama seda (Cynodon dactylon (L.) Pers).

Utilizou-se o delineamento experimental em blocos ao acaso, com tratamentos arranjados em parcelas subdivididas com quatro repetições. As parcelas principais representaram a aplicação de herbicida. Os tratamentos foram: VC: vegetação campestre ( $\mathrm{s} /$ amendoim e s/ herbicida); $\mathrm{VC}+\mathrm{A}+\mathrm{H}$ : vegetação campestre + amendoim + herbicida; $\mathrm{A}$ : amendoim $+\mathrm{s} /$ herbicida; $\mathrm{A}+\mathrm{H}$ : amendoim + herbicida; $\mathrm{A}+\mathrm{Az}$ : amendoim + azevém $+\mathrm{s} /$ herbicida; $\mathrm{A}+\mathrm{Az}+\mathrm{H}$ : amendoim + azevém + herbicida. A aplicação de 3,0L ha ${ }^{-1}$ de herbicida glifosato (480 Agripec) foi realizada em 26/10/2007. Aárea foi submetida, no dia 09/11/2007, à gradagem leve para corte do material dessecado e incorporação de calcário (2 toneladas ha $\left.{ }^{-1}\right)$ e $200 \mathrm{~kg} \mathrm{ha}^{-1}$ de adubo na formulação 0-20-25 $\left(\mathrm{N}-\mathrm{P}_{2} \mathrm{O}_{5}-\mathrm{K}_{2} \mathrm{O}\right)$. A semeadura a lanço de amendoim forrageiro cv. 'Amarillo' foi realizada em 10/11/2007, utilizando-se 10kg ha $^{-1}$ de sementes inoculadas com Bradyrhizobium spp.. Devido ao baixo estande de plantas de amendoim, de 21 a $30 / 12 / 2007$, realizou-se plantio, utilizando mudas enraizadas da mesma cultivar. O plantio foi realizado em linhas espaçadas de $0,50 \mathrm{~m}$ com uma muda a cada $0,50 \mathrm{~m}$ na linha, deixando-se aproximadamente $2 / 3 \mathrm{da}$ muda sob o solo. A sobressemeadura do azevém anual (Lolium multiflorum Lam.) cv. 'Comum' ocorreu a lanço, na densidade de $20 \mathrm{~kg} \mathrm{ha}^{-1} \mathrm{em} 16 / 04 / 2008$. Uma avaliação da composição florística e da estrutura da vegetação foi realizada, antes da aplicação dos tratamentos, de 15 a 24/10/2007, utilizando-se o método do ponto (LEVY \& MADEN, 1933) modificado. Foram identificadas as espécies vasculares tocadas com uma haste de aço de $30 \mathrm{~cm}$ de comprimento que era deslocada em intervalos de $10 \mathrm{~cm}$ sobre uma trena de $10 \mathrm{~m}$ estendida que define uma linha fixa. A cada repetição por tratamento, duas linhas foram dispostas de forma sistemática no centro da subparcela com espaçamento de $3 \mathrm{~m}$ entre elas, totalizando 200 pontos. Um segundo inventário da vegetação foi realizado de 14 a 28/10/2008, seguindo o método do ponto, já descrito anteriormente. As linhas foram novamente localizadas para cada tratamento, nas primaveras de 2007 e 2008. A suficiência amostral foi verificada através da relação entre o número cumulativo de espécies amostradas e o tamanho da amostra - Curva do Coletor (CAIN, 1938), ajustada pela regressão logarítmica $y=a \cdot \ln (x)+b$, em que y é o número esperado de espécies inéditas ocorrentes 
a cada $\mathrm{x}$ pontos. Para cada espécie encontrada no levantamento fitossociológico, foi calculada a frequência absoluta (FA) e a frequência relativa (FR), segundo MATTEUCI \& COLMA (1982). A diferença na frequência relativa da primavera de 2007, antes da aplicação dos tratamentos, para a primavera de 2008, após a aplicação dos tratamentos, foi computada. Os dados de frequência relativa das espécies, mantilho e solo descoberto em cada linha e ano foram submetidos à análise multivariada de ordenação, pelo método de coordenadas principais, com distância euclidiana como medida de semelhança.

\section{RESULTADOS E DISCUSSÃO}

Nos levantamentos realizados nos anos de 2007 e 2008, antes e após a aplicação dos tratamentos, respectivamente, foram identificadas 21 espécies forrageiras, além de outras ciperáceas e não forrageiras, as quais são espécies indesejáveis com frequência relativas inferior a $0,10 \%$ na área em estudo (Tabela 1 ).

A família Poaceae foi a mais expressiva em número e frequência de espécies. A frequência relativa média dessa família foi de $51,3 \%$ e 54,9\% na primavera de 2007 para os tratamentos sem e com herbicida, respectivamente. Considerando as espécies da família Fabaceae, com exceção de Arachis pintoi, espécie não espontânea na pastagem, a frequência relativa média de leguminosas foi de $0,88 \%$ e $0,41 \%$ na primavera de 2007 para os tratamentos sem e com herbicida, respectivamente (Figuras 1 e 2).

Os testes de aleatorização indicaram que não houve efeito significativo da sobressemadura de azevém sobre a frequência relativa das espécies. Entretanto, houve efeito $(\mathrm{P}=0,0541)$ da aplicação do herbicida glifosato. Nas figuras 1 e 2, são mostrados os valores de frequência relativa dos componentes nas linhas de cada bloco.

A utilização do herbicida glifosato resultou em uma maior frequência relativa das leguminosas de verão, em função do estabelecimento de Arachis pintoi, quando comparada ao tratamento sem herbicida (Figuras 1 e 2), em que Desmodium incanum (D. incanum) foi a leguminosa nativa de maior frequência. O controle da vegetação antes da introdução da leguminosa garantiu uma menor competição com as espécies existentes e, com isso, sua melhor implantação e estabelecimento, visto que é uma espécie de desenvolvimento inicial lento (VALENTIM et al., 2001). Observou-se que a sobressemeadura de azevém anual no período de outono-inverno proporcionou ao amendoim forrageiro melhores condições durante o período de inverno e resistência às condições climáticas adversas, resultando em plantas sadias e mais vigorosas na primavera.

$\mathrm{Na}$ figura 2, pode-se verificar a ação do glifosato, no primeiro ano, de mudança na fisionomia do campo. Observou-se uma uniformização da vegetação pelo herbicida das quatro linhas amostradas. A vegetação na primavera de 2007 era mais distinta entre si e, na primavera de 2008, após a aplicação do herbicida, tornou-se mais semelhante.

Verificou-se que, na primavera de 2007, entre as gramíneas de inverno, Lolium multiflorum e Piptochaetium montevidensis (P. montevidensis) apresentaram maior frequência. Entretanto, na primavera seguinte, somente Lolium multiflorum $(\boldsymbol{L}$. multiflorum) apresentou sua frequência elevada. $\boldsymbol{P}$. montevidensis, gramínea nativa pouco competitiva, foi reduzida na primavera de 2008. Provavelmente, devido à competição por luz e nutrientes, além do efeito de cobertura exercido por L. multiflorum e Cynodon dactylon. As gramíneas de verão que apresentaram maiores frequências na primavera de 2007 foram Cynodon dactylon (C. dactylon), Eragrostis plana (E. plana), Paspalum notatum (P. notatum) e Paspalum nicorae (P. nicorae) (Figura 1).

Na figura 1 , observa-se que, no tratamento sem herbicida, houve redução de $\boldsymbol{P}$. notatum, provavelmente devido a outros fatores, como a competição com outras espécies, tais como $C$. dactylon, L. multiflorum e D. incanum, que apresentaram frequências maiores. As gradagens realizadas na área para incorporar o adubo e promover o aumento da superfície de contato da semente de amendoim forrageiro com o solo aumentaram a superfície de solo exposta e, juntamente com o déficit hídrico observado durante o período experimental, também podem ter contribuído para um aumento da frequência de gramíneas de verão, principalmente, C. dactylon e Eragrostis airoides (E. airoides). A frequência relativa das gramíneas de inverno (GI) não apresentou um padrão de crescimento entre as linhas e os blocos na primavera de 2007 para a de 2008. As gramíneas de verão $(\mathrm{GV})$ e leguminosas de verão $(\mathrm{GV})$ tiveram suas frequências relativas aumentadas no mesmo período. Em sentido inverso, as espécies não forrageiras (NF), mantilho $(\mathrm{M})$ e solo descoberto $(\mathrm{S})$ reduziram suas frequências da primavera de 2007 para 2008.

Outras gramíneas tiveram uma redução considerável quando se aplicou o herbicida, tais como: C. dactylon, E. airoides, E. plana, P. notatum e $\boldsymbol{P}$. montevidensis. SANT'ANNA \& NABINGER (2007) afirmaram que o plantio direto ou sobressemeadura de forrageiras de inverno sobre a pastagem nativa, sem a sua remoção são as metodologias mais adequadas e sustentáveis. 
Tabela 1 - Componentes da flora identificados, mantilho e solo descoberto em área com vegetação campestre secundária. Capão do Leão, RS, nas primaveras de 2007 e 2008.

\begin{tabular}{|c|c|c|c|}
\hline \multirow[b]{2}{*}{ Família } & \multirow[b]{2}{*}{ Espécie } & \multicolumn{2}{|c|}{---------------------Ano-- } \\
\hline & & 2007 & 2008 \\
\hline \multirow[t]{17}{*}{ Gramineae (Poaceae) } & Agrostis montevidensis Spreng. ex Nees & $\mathrm{x}$ & \\
\hline & Axonopus affinis Chase & $\mathrm{x}$ & \\
\hline & Briza minor $\mathrm{L}$. & $\mathrm{x}$ & \\
\hline & Briza subaristata Lam. & $\mathrm{x}$ & $\mathrm{x}$ \\
\hline & Calamagrostis viridiflavescens (Poir.) Steud. & $\mathrm{x}$ & \\
\hline & Chloris spp. & $\mathrm{x}$ & $\mathrm{x}$ \\
\hline & Cynodon dactylon (L.) Pers. & $\mathrm{x}$ & $\mathrm{x}$ \\
\hline & Eragrostis airoides Nees & $\mathrm{x}$ & $\mathrm{x}$ \\
\hline & Eragrostis plana Nees & $\mathrm{x}$ & $\mathrm{x}$ \\
\hline & Lolium multiflorum Lam. & $\mathrm{x}$ & $\mathrm{x}$ \\
\hline & Mellinis repens (Willd.) Zizka & & $\mathrm{x}$ \\
\hline & Paspalum notatum Flügge & $\mathrm{x}$ & $\mathrm{x}$ \\
\hline & Paspalum nicorae Parodi & $\mathrm{x}$ & $\mathrm{x}$ \\
\hline & Paspalum plicatulum Michx. & $\mathrm{x}$ & $\mathrm{x}$ \\
\hline & Piptochaetium montevidensis (Spreng.) Parodi & $\mathrm{x}$ & $\mathrm{x}$ \\
\hline & Setaria parviflora (Poir.) Kerguélen & $\mathrm{x}$ & $\mathrm{x}$ \\
\hline & Sporobolus indicus (L.) R. Br. & $\mathrm{x}$ & $\mathrm{x}$ \\
\hline \multirow[t]{4}{*}{ Leguminosae (Fabaceae) } & Arachis pintoi Krapov. \& W.C. Greg. & & $\mathrm{x}$ \\
\hline & Desmodium incanum DC. & $\mathrm{x}$ & $\mathrm{x}$ \\
\hline & Lupinus bracteolaris Desr. & & $\mathrm{x}$ \\
\hline & Trifolium polymorphum Poir. & $\mathrm{x}$ & \\
\hline Amaranthaceae & Amaranthus viridis $\mathrm{L}$. & & $\mathrm{x}$ \\
\hline \multirow[t]{3}{*}{ Asteraceae } & Ambrosia tenuifolia Spreng. & $\mathrm{x}$ & $\mathrm{x}$ \\
\hline & Baccharis trimera (Less.) DC. & $\mathrm{x}$ & \\
\hline & Soliva pterosperma (Juss.) Less. & & $\mathrm{x}$ \\
\hline Commelinaceae & Commelina diffusa Burm. f. & & $\mathrm{x}$ \\
\hline Caryophillaceae & Silene gallica $\mathrm{L}$. & & $\mathrm{x}$ \\
\hline Cyperaceae & Kyllinga vaginata Lam. & $\mathrm{x}$ & \\
\hline Iridaceae & Sisyrinchium micranthum Cav. & & $\mathrm{x}$ \\
\hline Malvaceae & Sida rhombifolia $\mathrm{L}$. & & $\mathrm{x}$ \\
\hline Onagraceae & Oenothera grandiflora L'Hér & & $\mathrm{x}$ \\
\hline Plantaginaceae & Plantago australis Lam. & $\mathrm{x}$ & $\mathrm{x}$ \\
\hline Primulaceae & Anagallis arvensis $\mathrm{L}$. & & $\mathrm{x}$ \\
\hline Rubiaceae & Richardia brasiliensis Gomes & & $\mathrm{x}$ \\
\hline \multirow[t]{5}{*}{ Solanaceae } & Solanum americanum Mill. & & $\mathrm{x}$ \\
\hline & Outras ciperáceas & $\mathrm{x}$ & \\
\hline & Outras não forrageiras & $\mathrm{x}$ & $\mathrm{x}$ \\
\hline & mantilho & $\mathrm{x}$ & $\mathrm{x}$ \\
\hline & solo descoberto & $\mathrm{x}$ & $\mathrm{x}$ \\
\hline
\end{tabular}

Verificou-se que, no tratamento com herbicida, houve uma redução na frequência de gramíneas de verão, principalmente, $\boldsymbol{C}$. dactylon. A competição exercida por Arachis pintoi e de $\boldsymbol{L}$. multiflorum, sobressemeado na vegetação campestre no outono-inverno, também podem ter sido responsáveis por esta redução (Figura 2). REIS (2009) relata o efeito positivo da aplicação de herbicida no $1^{\circ}$ ano sobre o estabelecimento e produtividade de azevém no $2{ }^{\circ}$ ano.

Assim como $\boldsymbol{C}$. dactylon, a aplicação do herbicida reduziu a frequência do capim Annoni-2, desse modo, diminuindo, provavelmente, seu efeito alelopático e possibilitando o aumento na frequência de amendoim 


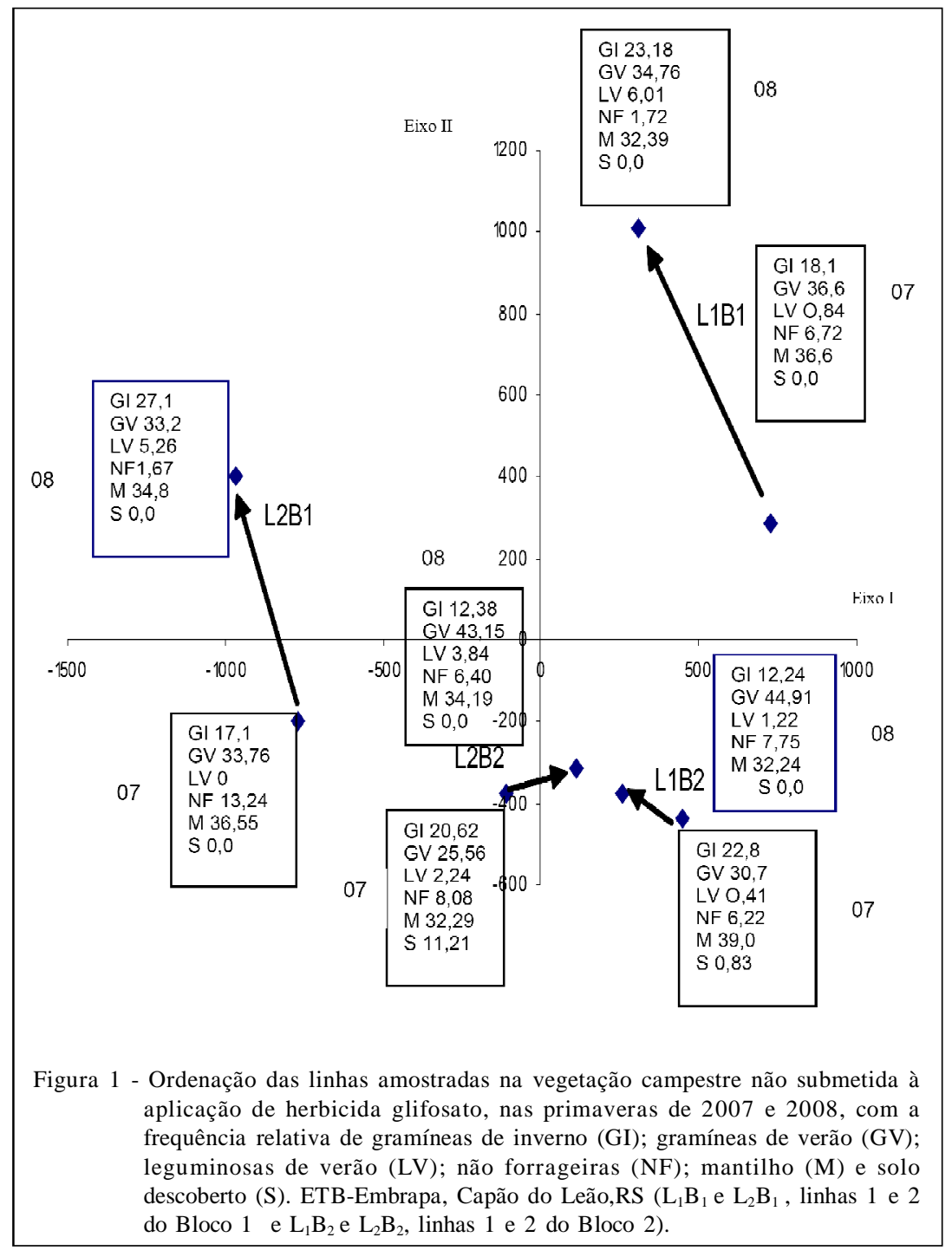

forrageiro, mas promovendo o aparecimento de outras plantas não forrageiras, como Plantago australis, Solanum americanum e Silene gallica.

O efeito da aplicação de glifosato diminui as frequências de gramíneas nativas estivais (Figura 2), especialmente as do gênero Paspalum. GOMAR et al. (2004) verificaram, com o uso de glifosato, uma redução na frequência de Paspalum plicatulum e $\boldsymbol{P}$. notatum. Essa gramínea estolonífera é suscetível a esse manejo, devido ao estolão estar na superfície do solo, evidenciando sua dificuldade em rebrotar. BOGGIANO \& BERRETTA (2006) consideram que a perturbação dos campos por herbicidas sistêmicos de ação total provoca mudanças irreversíveis na composição florística com o desaparecimento de espécies. Isso também ocorreu no presente trabalho, verificando-se o desaparecimento de várias gramíneas, tais como: Axonopus affinis, Calamagrostis viridiflavescens, Chloris spp. e P. nicorae.

A ação do herbicida modificou a ocorrência das espécies presentes na vegetação campestre. Foi observado um aumento nas frequências relativas das gramíneas de inverno (GI) para azevém e leguminosas de verão (LV) para amendoim, da primavera de 2007 para 2008. Entretanto, gramíneas de verão (GV), não forrageiras (NF), mantilho (M) e solo descoberto (S) sofreram redução no mesmo período.

\section{CONCLUSÃO}

A introdução de amendoim forrageiro é beneficiada pela aplicação de glifosato. Entretanto, 


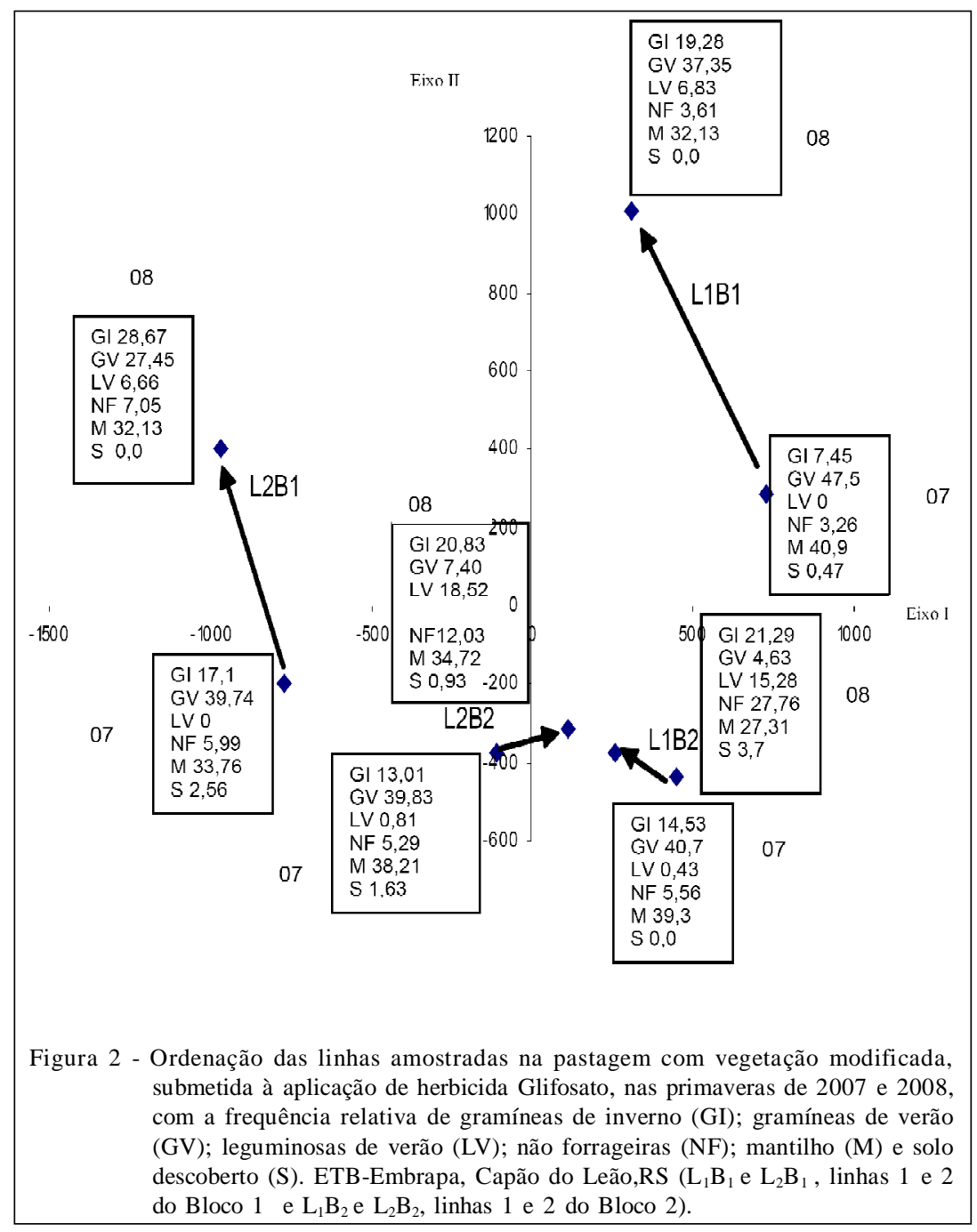

essa prática provoca redução significativa de espécies nativas de interesse forrageiro. A presença do azevém anual proporciona um ambiente favorável para o amendoim forrageiro durante o período de inverno.

\section{REFERÊNCIAS}

AMARANTE JUNIOR, O.P. et al. Glifosato: propriedades, toxicidade, usos e legislação. Química Nova, v.25, n.4, p.589593, 2002. Disponível em: <http://www.scielo.br/pdf/qn/v25n4/ 10534.pdf $>$. Acesso em: 08 set. 2009. doi: S010040422002000400014 .

BANDINELLI, D.G. et al. Variáveis morfogênicas de Andropogon lateralis Nees. submetido a níveis de nitrogênio nas quatro estações do ano. Ciência Rural, v.33, n.1, p.71-76, 2003.

BOGGIANO P.; BERRETTA E. Factores que afectan la biodiversidad del campo natural. In: REUNIÃO DO GRUPO TÉCNICO EM FORRAGEIRAS DO CONE SUL-GRUPO
CAMPOS, 21., 2006 Pelotas, RS. Anais... Pelotas: Embrapa Clima Temperado, 2006. p.93-104.

CAIN, S.A. The species- area curve. American Midland Naturalist, v.19, p.573-581, 1938.

FLORES, R.A. et al. Produção de forragem de populações de azevém anual no estado do Rio Grande do Sul. Revista Brasileira de Zootecnia, v.37, n.7, p.1168-1175, 2008. Disponível em: <http://www.revista.sbz.org.br/artigo/ idex.php?artigo7014>. Acesso em: 10 ago. 2009. doi: S151635982008000700005 .

GOMAR, E.P. et al. Semeadura direta de forrageiras de estação fria em campo natural com aplicação de herbicidas I.Produção de forragem e contribuição relativa das espécies. Ciência Rural, v.34, n.3, p.761-767, 2004. Disponível em: <http:// www.scielo.br/pdf/\%0D/cr/v34n3/a17v34n3.pdf >. Acesso em: 05 jul. 2009. doi: S0103-84782004000300017.

KRAPOVIKAS, A.; GREGORY, W.C. Taxonomia del gênero Arachis (Leguminosae). Bonplandia, v.8, n.1-4, p.1-186, 1994. 
LEVY, E.B.; MADDEN, E.A. The point method of pasture analysis. New Zeland Journal of Agriculture, v.46, p.267279, 1933. Disponível em: <http://www3.interscience.wiley.com/ journal $/ 119887177 / 1$ bstract?CRETY $=1 \&$ RETRY $=0>$. Acesso em: 15 dez. 2008. doi:10.1111/j.1365-2494.1957.tb00977.x.

MARASCHIN, G.E. Sistemas de pastejo. In: PEIXOTO, A.M. et al. (Eds.). Pastagens: fundamentos da exploração da exploração racional. 2.ed. Piracicaba: FEALQ, 1994. Cap.14, p.155-188.

MATTEUCI, S.D.; COLMA, A. Metodologia para el studio de la vegetación. Washington: Secretaria General da la Organización para los Estados Americanos, 1982. 169p.

MONQUERO, P.A. Dinâmica populacional e mecanismos de tolerância de espécies de plantas daninhas ao herbicida Glyphosate. 2003. 99f. Tese (Doutorado em Fitotecnia) - Escola Superior de Agricultura "Luiz de Queiroz", Universidade de São Paulo, Piracicaba, SP.

MOTA, F.S. Estudo do clima do Rio Grande do Sul segundo o sistema de W. Köeppen. Revista Brasileira de Geografia, v.13, n.2, p.275-284, 1951. Disponível em: <http://www.scielo.br/ scieloOrg/php/reflinks.php>. Acesso em: 20 ago. 2009. doi: S0102-3306200500040000600022.

NASCIMENTO, I.S. Adubação e utilização de amendoim forrageiro (Arachis pintoi Krapovikas \& Gregory) cv. 'alqueire'. 2004. 75f. Tese (Doutorado em Zootecnia) Faculdade de Agronomia "Eliseu Maciel"/Universidade Federal de Pelotas, Pelotas, RS.
PARIS, W. Produção animal em pastagem de coastcross1 consorciada com Arachis pintoi com em sem adubação nitrogenada. 2006. 128f. Tese (Doutorado em Zootecnia) - Universidade Estadual de Maringá, Maringá, PR.

REIS, J.C.L.; FONTANELI, R.S. Melhoramento de pastagens através da introdução de forrageiras de inverno visando maximizar o uso do solo. In: SIMPÓSIO DE FORRAGICULTURA E PASTAGENS, 2000, Lavras, MG. Anais... Lavras: Universidade Federal de Lavras, 2000. p.237-271.

REIS, J.C.L. O uso de herbicidas para a introdução de forrageiras nos campos e seus efeitos na flora campestre. In: PILLAR, V.D.P. et al. (Eds.). Campos sulinos - conservação e uso sustentável da biodiversidade. Brasília: MMA, 2009. Cap. 21 , p.266-273.

RISSO, D.F; BARRETTA, E.J. Mejoramiento de campos Curso de actualización sobre manejo y conservación de suelos. Montevideo: Facultad de Agronomia da Universidad de la Republica, 1996. p.40-60.

SANT'ANNA, D.M.; NABINGER, C. Adubação e implantação de forrageiras de inverno em campo nativo. In: DALL'AGNOLL, M. et al. (Ed.) Simpósio de forrageiras e produção animal, 2. Porto Alegre: Formato Artes Gráficas, 2007. p.123-156.

STRECK, E.V. et al. Solos do Rio Grande do Sul. 2.ed Porto Alegre: UFRGS, 2008. 107p. ISBN 85-7025-648-5.

VALENTIM, J.F. et al. Amendoim-forrageiro cv. 'Belmonte': leguminosa para a diversificação das pastagens e conservação do solo no Acre. Rio Branco: EMBRAPA - CPAF/AC, 2001. 18p. 